\title{
Research on Interactive Platform between School and Enterprise Based On Mobile Cloud Technology
}

\author{
Zhang Shujun \\ Department of computer and Information Engineering \\ Chengde Petroleum College \\ Cheng De, China \\ zhsjun@sina.com
}

\author{
Zhang Liming \\ Department of Mechanical Engineering \\ Chengde Petroleum College \\ Cheng De, China \\ 36752920@qq.com
}

\begin{abstract}
School-enterprise cooperation has been studied for many years, but for most colleges and universities, School-enterprise cooperation in depth and breadth is far from enough. The paper analyzes the problems and reasons in school-enterprise cooperation, and raises a solution to build the Interactive platform between school and enterprise based on mobile cloud computing technology. The platform uses a cloud storage service to solve the problem of education and teaching resource storage, combines mobile devices and cloud computing. From the interaction content and form with the three parties of school, students and enterprise, gives the whole design idea and method of the schoolenterprise interaction platform. Through this platform, enterprise can understand the situation of scientific research, offering professional courses of school and the ability of the professional students, the school can understand the demand for production, design and talent of enterprise, the students can pay attention to the demand for qualified people by companies, define their striving goal, take their courses online whenever and wherever. It implements the seamless joint for school, enterprise and students.
\end{abstract}

Keywords- Cloud Computing; School-enterprise cooperation; Online Learning Platform; Communicate; elearning

\section{INTRODUCTION}

School-enterprise cooperation means an information sharing mechanism between academic institute and market players[1]. This idea, in these years, has not transformed into something satisfactory. The primary reason is insufficient communication.

Optimists in this field have shifted their focus to a new technology --- Mobile Cloud Computing (hereinafter "MCC") that could possibly accommodate this unsatisfied idea of communication. MCC comparing with traditional Cloud Computing share the same idea of providing service through the Cloud. Since 2010, this technology has largely developed with tremendous prosperity in different industries[2].

The question of connecting the relevant parties efficiently in this mechanism of communication--enterprises, schools and students, becomes the prior need to be satisfied by MCC[3], which could make the system more convenient, friendly, dynamic. Meanwhile, internally, this system can further developed into a place where generations of students, teachers, alumni can share their perspective and create chances.

\section{IMPERFECTIONS WITHIN THE PRESENT SYSTEM}

Enterprises have limited chance and resource to know and understand current education: the curriculum constructions, students' personal developments. This makes enterprises hard to determine qualified labor forces for their own developments.

On the other side, teachers and students lack the necessary information to clearly know about the market: especially for students to know the basic needs of their future employers, which would in turn has implications for their own development, career plans. However, this can hardly be achieved in the present circumstances[4].

What is in common for both sides is insufficient communication. How can make enterprises and school have interactive respond to other's needs for both benefits. We propose a solution of building up a platform using mobile smart devices and mobile cloud computing technology that can truly energies both sides to collectively contribute a interactive system.

\section{System DeSIGN}

\section{A. General Structure}

This system will accommodate the need of communication, which embraces two organs: the system of enterprises' websites and the system of education resources. This combination of resources will benefit enterprises' human resource management and schools' publishing best course materials online. The general structure of the system is shown in Figure 1.

Within this system, enterprises can pose its statement about its culture, employment and products in the system for a broad coverage among students and teachers. Besides the education materials provided within this system can be used not only for students, but also for employees in the enterprises[5]. All users can get access to the system through PC or online mobile devices. 


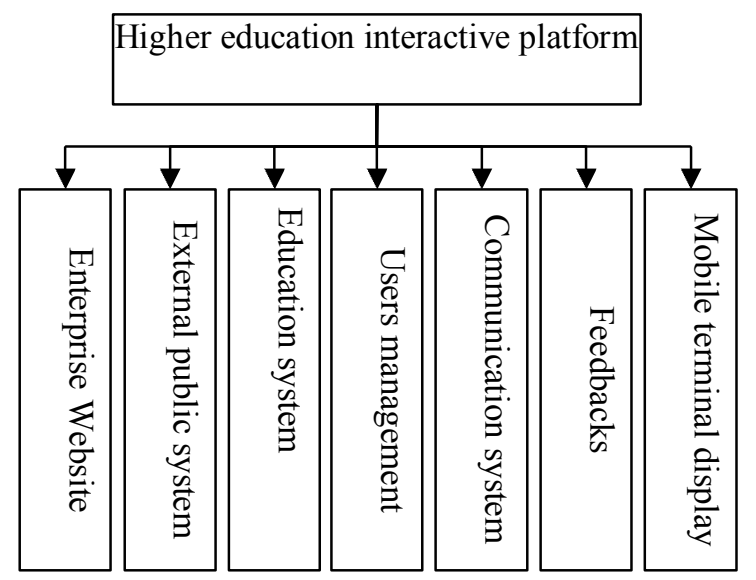

Figure 1. System Models

\section{B. Constructions of users}

Within this system, users are divided into enterprise users, administrators, teachers, students and alumni. Different experiences will be provided respectively. Users can follow each other like in a social media, which could enable students to know about the requirements of employers and adjust himself/herself accordingly. Enterprise users or alumni can use the system to develop themselves with professional knowledge[6]. With further communication venues provided in the system, every user can get access to his/her interest.

Each user in the system is independent and interrelated. Users can set up mutual concern, discussion groups and other forms, the formation of every kind of circle of friends. Customer relationship is shown in Figure 2.

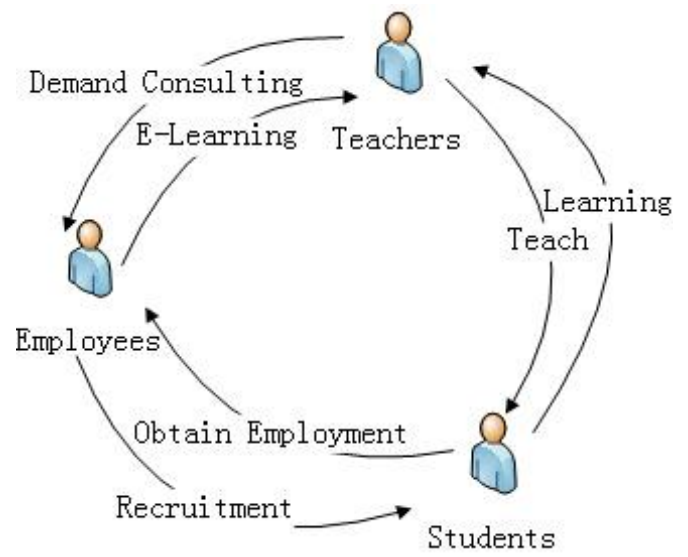

Figure 2. Customer relationship in the system

\section{SYSTEM ESTABLISHMENTS}

\section{A. Cloud storage}

The system relies on Amazon S3 as cloud storage service provider that uses PHP, Zend Framework application construction agreement to achieve the purpose. Amazon provides visiting key and secret key for developer. These keys will be useful when developer uses PHP to set up a cloud system. Since most of the time the system seldom need changes, the key will be kept in PHP's setting documents. Even changes are needed, not much has to be done except PHP setting documents[7], which overall increase the security level.

\section{[amazon]}

accessKey $=0123456789$ ABCDEFGHIJ

secretKey $=0123456789$ abcdefghiABCDEFGHI 123456

$7890 \mathrm{AB}$

ownerId=123456789012

[nirvanix]

username $=\mathrm{cdpc}$

password $=$ cdpccloud

appKey=01234567-89ab-cdef-0123-456789abcdef

With a certificate key, users can uses PHP system to get access to S3 cloud server to storage and manage documents, which increase storage dramatically[8]. This is especially beneficial to enterprise since it reduce investments.

\section{B. Website administration}

Websites is one of the most effective ways of demonstrating a corporation. However, most of the enterprises do not have professionals with this regard to truly use this venue of promotion. On the other hand, students and teachers within the college are looking for such opportunity to truly apply what they have learned in managing a website. The system we suggested will provide opportunities for both sides

For construction of a website that satisfy different enterprises needs of demonstration, the usual way is to use template and adjust according to specific needs within the system. This template include data process and display of the website. Data process means searching data base to find relative data and display in the website by HTML[9]. The relative data process module is shown in the following:

function data process(\$themeprocess, \$datafromdb) \{

if(isset(\$datafromdb\&\&\$themeprocess is function) \{ return \$themeprocess(\$datafromdb);

\}

$$
\text { \} }
$$

Here, \$themeprocess is provided as a function to every module, which can convert the data to display shown in the website. As been shown in the following: function theme_process(\$fromdb) \{ foreach $(\$$ fromdb as $\$ \mathrm{k}=>\$ \mathrm{v})\{$ \$pagevars $[\$ \mathrm{k}]=\$ \mathrm{v}$;

$$
\text { \} }
$$

//call template handler

\$output = load_template("template.html"); \$output=set_page_vars(\$output, \$pagevars); return \$output;

\}

Website display can be easily achieved by imputing relevant parameters. The basic code are provided below: $<$ title $><$ ?php echo \$page_title; ? $></$ title $>$

$<$ body $>$

$<$ div id="page_content" $>$

$<$ ?php echo \$content; ?>

$</$ div $>$

$<$ div id="copyright" $>$ 


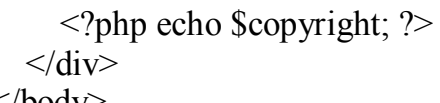

$</$ body $>$

For enterprises, they can choose the template they prefer. Further, system provides different settings of display in holidays or other special occasions, which makes the system more friendly and useful for enterprises.

Recruitment is one of the important functions in enterprise website system. The interactive Platform system changes the traditional mode of post job, which sets the job requirements of enterprise based on the standard occupation requirements in order to facilitate the statistics. For example, for the requirements of computer software development language in software development jobs, when enterprises release their job postings, the system will provide as much as possible indicators for enterprises to choose one or more as the first index. Example is as follows:

\section{$\square \quad$ Java \\ $\square \quad$ ASP.NET}

$\square \quad$ PHP

$\square$ HTML、CSS、JavaScript

Next, the secondary level index is respectively arranged for the each first level index for enterprises to choose. For example, the secondary level index on the knowledge of the language is set as follows:

Know, know the grammar of PHP, but no project experience

Familiar, there are some development experience

O Mastery, independent development

The system will analysis the issue information on business and gives the statistical results. According to these, teachers and students can know the required knowledge for that position. Table 1 shows the results for the enterprise is demand of computer software development language recruitment.

TABLE 1. Software Development Language Demand

\begin{tabular}{|c|c|c|c|c|}
\hline \multicolumn{1}{|c|}{$\begin{array}{c}\text { Computer } \\
\text { language }\end{array}$} & $\begin{array}{c}\text { HTML、 } \\
\text { CSS、 } \\
\text { JavaScriipt }\end{array}$ & Java & ASP.NET & PHP \\
\hline $\begin{array}{l}\text { The statistical } \\
\text { results of } \\
\text { enterprise } \\
\text { demand }\end{array}$ & $100 \%$ & $75 \%$ & $55 \%$ & $65 \%$ \\
\hline
\end{tabular}

\section{Education resources}

Professional education has already determined a resource base to be one of the body of the curriculum. This interactive platform certainly takes this function of education resources important, which means providing teachers access to publish and manage contents. This system will enable teachers to focus on their job of teaching and research instead of the development of the whole system.

The management of this resource base will follow the similar path as enterprise websites, which also has templates. Further, for particular news of education, this part of the system will provide more powerful functions for word processing, especially concerning uploading, downloading.

In terms of student users, the system provides an intense body of sources concerning texts, projects that can be easily searched and used. Meanwhile, students can finish courses online and tests.

The resources more specifically refers to teaching plans, course materials (PPT, PDF), experiment guide, experiment plan, course standard, course video, case studies, test data base and others. These contents are all stored online within the cloud sever. The resources catalog is demonstrated in Figure 2.

In order to facilitate user's online learning, resource database system provides online play and online reading system, which makes the learner use resources without having to download them. So, the system provide automatic resource conversion function. Materials can be converted into forms of PDF or HTML for reading, or can be displayed online by HTML 5 tag technology if they are video, audio.

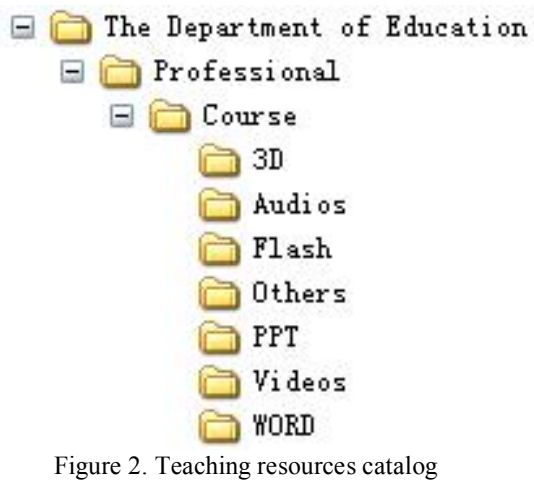

\section{Mobile terminal display}

Users reading habit and Internet usage are more relying on mobile terminal. This system also provides mobile terminal display in order to help users, especially teachers and students, get access from time to time anywhere[10]. Enterprise users also can get access to terminal displays which help them to build website particularly for mobile terminals. Mobile terminal displays will apply HTML 5 in order to enhance users experience, which means better communication. The whole website will be constructed in a separate structure which includes header, content and footer. The main body base on HTML 5 is shown below:

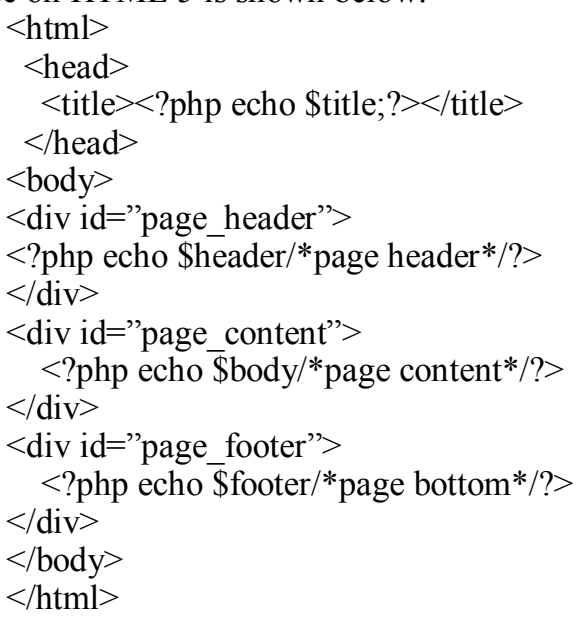


This solution expands the attention of developers to different fields, makes development easier and increases development efficiency. When user browses the client, the system can detect the terminal Computer and mobile device, and adapt the template accordingly.

\section{RESULTS ANALYSIS}

This system materially benefits schools and enterprise in practice. It has a good effect and results in the aspect of school enterprise cooperation and sharing of educational resources, which has solve the practical problem for the enterprise and school and truly increase communications. This can be shown in following aspects[6]:

The system solves the enterprise talent demand problem, clarifies enterprises needs and provides strong basis for colleges and universities to set course;

The Interactive platform Provides professional guidance to the school to the talent training scheme. The school to the professional personnel training program is serious discrepancy with the enterprise need, but now, through the interactive platform[9], majors within schools have also adapted to enterprises' requirements and relevant information provided by graduated students.

Students have a better knowledge about the market, which further facilitate their perception about the courses they have.

Alumni can also get access to these resources, which help their continuous improvement.

The system provides strong evidence and communications for students to have their own career plans;

Teachers can finally be free from what has taken them lot of resource to develop a resource database, and invest more effort in other works[10];

A convenient system which connects the enterprise with school minimizes its cost of building a website, where it can pose information and statements.

\section{CONCLUSION}

By using cloud technology, this interactive system accommodates the prior needs of enterprise; students and teachers, which can be a greater degree of meet the needs of the three aspects and further facilitate communication for users. During the whole experiment, the major issue arises in cloud storage. However, with dedicated help from professional personals from different enterprises, things become possible one by one. Through continuous improvement, In application, the school and enterprise are united in praise for this system. In future research, the system will become more automatic, and provide enterprise, schools more convenient by adding automation of page processing to dynamic edit, process website resources. Besides, in order to help students to study and follow the market and have a basis to master their own direction of development. New function will be provided to provide career plan and analysis. This system can also be applied in different educational facilities.

\section{REFERENCES}

[1] Lin Liping, "The Analysis of Existing Problens and Countermeasures of Cooperation between School and Enterprise", Journal of Huainan Vocational \& Technical College, vol.11, May. 2011, pp. 36-40, doi: 10.3969/j.issn.1671-4733.2011.05.012.

[2] Li Zhengwei,Wang Dizhao and Li Xiaomiao, "Status Quo and Influence Factors of University Industry Collaboration: Evidence of Zhejiang Province", Science \& Technology Progress and Policy, vol. 29, 2012, pp. 150-154, doi: 10.6049/kjjbydc.2011080111.

[3] Wang Yanli and Xue Yaowen, "The empirical analysis on promoting the effects of university industry cooperation on the perspective of enterprises", Studies in Science of Science, vol. 28 Jul. 2010, pp.1082-1087.

[4] Lv Pu and Lin Li, "Modeling and Simulating of University Enterprise Cooperation System in Context of Open Innovation," Science \& Technology Progress and Policy, vol. 29, 2012, pp. 112 117, doi: $10.6049 / \mathrm{kjjbydc} .201208 \mathrm{C} 101$.

[5] Meng Yuanbei and Zha Jide, "Interaction between the cooperative development and higher vocational colleges and enterprises,' Higher Education Exploration, vol.3, Mar. 2013, pp. 119-122, doi: 10.3969/j.issn.1673-9760.2013.03.024.

[6] Lei Wanyun, "Cloud computing-Enterprise Informatization Construction Strategy and Practice," Beijing: Tsinghua university press, 2010

[7] Li yI, "Design and implementation of an interactive website," Beijing: Beijing University of Posts and Telecommunications press, 2011.

[8] Michael Bowers, Dionysios Synodinos and Victor Sumner, "HTML5 and CSS3 design patterns," Beijing: People's Posts and Telecommunications Press,2013.

[9] Tang Junkai, "HTML5 mobile Web Development Guide," Beijing: Electronics industry Press,2012.

[10] Huang Junshi, "Android and PHP development best practices," Beijing: Machinery Industry Press, 2013 